\title{
Total Magnetic Resonance Imaging of Cerebral Small Vessel Disease Burden Predicts Dysphagia in Patients with a Single Recent Small Subcortical Infarct
}

\section{Lulu Zhang}

First Affiliated Hospital of Soochow University

\section{Xiang Tang}

First Affiliated Hospital of Soochow University

\section{Yidan Li}

First Affiliated Hospital of Soochow University Juehua Zhu

First Affiliated Hospital of Soochow University

Dongxue Ding

First Affiliated Hospital of Soochow University

\section{Yun Zhou}

First Affiliated Hospital of Soochow University

Shanshan Diao

First Affiliated Hospital of Soochow University

\section{Yan Kong}

First Affiliated Hospital of Soochow University

\section{Xiuying Cai}

First Affiliated Hospital of Soochow University

\section{Ye Yao}

Fudan University

Qi Fang ( $\square$ fangqi@suda.edu.cn )

First Affiliated Hospital of Soochow University

\section{Research Article}

Keywords: acute ischemic stroke, recent small subcortical infarct, magnetic resonance imaging, small vessel disease, post-stroke dysphagia

Posted Date: March 1st, 2021 
DOI: https://doi.org/10.21203/rs.3.rs-253887/v1

License: (c) (1) This work is licensed under a Creative Commons Attribution 4.0 International License. Read Full License

Version of Record: A version of this preprint was published at BMC Neurology on January 3rd, 2022. See the published version at https://doi.org/10.1186/s12883-021-02518-9. 


\section{Abstract \\ Background}

The study was performed to identify the association between total magnetic resonance imaging burden of small vessel disease and occurrence of post-stroke dysphagia in patients with a single recent small subcortical infarct.

\section{Methods}

All patients with a magnetic resonance imaging-confirmed single recent small subcortical infarct underwent the water-swallowing test and volume-viscosity swallow test within the first 24 hours following admission to assess swallowing. Demographic and clinical data were extracted from our stroke database. Based on brain magnetic resonance imaging, we independently rated the presence of cerebral microbleeds, lacunes, white matter hyperintensities and enlarged perivascular spaces. The presence of each small vessel disease feature was summed in the total small vessel disease burden, ranging from $0-$ 4.

\section{Results}

In total, 308 patients with a single recent small subcortical infarct were enrolled. Overall, $54(17.5 \%)$ were diagnosed with post-stroke dysphagia. The risk factors related to post-stroke dysphagia included the following: older age, National Institute of Health Stroke Scale, higher C-reactive protein levels and higher fibrinogen levels. Based on multiple logistic regression, two variables with the most significant associations, namely, National Institute of Health Stroke Scale and total small vessel disease burden, were combined with age, gender, history of hypertension, C-reactive protein level and fibrinogen level.

\section{Conclusions}

Dysphagia in patients with a single recent small subcortical infarct resulted from severe small vascular disease, which was associated with systemic inflammation. This information might provide a new antiinflammatory treatment for post-stroke dysphagia in the future.

\section{Introduction}

Post-stroke dysphagia (PSD) was a common disabling symptom associated with pneumonia, malnutrition and poor clinical outcomes[1]. PSD rates were particularly high among acute ischemic strokes (AIS) patients with older age, severe stroke and larger infarcts[2]. Brainstem strokes represented another risk factor for dysphagia and resulted in the greatest swallowing compromise[3]. 
However, PSD also occurred in up to one-fifth of patients with a single recent small subcortical infarct (RSSI)[4]. RSSI was previously defined as lacunar infarct and was noted $25 \%$ of all AIS patients[5]. RSSI was thought to result from the occlusion of a small, single perforating artery supplying subcortical areas, including the basal ganglia, thalamus, centrum semiovale and pons[6]. The pathogenesis of PSD following a single RSSI was unclear. A prior retrospective study reported that PSD in supratentorial RSSI may result from bilateral pyramidal tract damage caused by pre-existing contralateral lesions (including lacunes or confluent white matter hyperintensities $(\mathrm{WMH}))[1]$. Another study found that PSD in patients with a single RSSI was expected, especially among those with severe stroke, pontine infarcts and severe $\mathrm{WMH}[4]$.

Multiple subcortical regions were also associated with abnormal swallowing, which may provide an interconnection between cortical swallowing centres and the central pattern generator[7]. These anatomic structures and pathways may not only be disrupted by RSSI but also by coexisting damage of small vessel disease (SVD)[8]. The terrm cerebral SVD described a range of neuroimaging features, which had long been implicated with cognitive impairment, stroke and gait disorder[5]. Magnetic resonance imaging (MRI) markers of SVD included cerebral microbleeds (CMBs), lacunes, WMH, enlarged perivascular spaces (ePVS) and brain atrophy[9]. The exact mechanism of SVD was not well known and thought to result from damage to the perforating cerebral arterioles, capillaries, and venules, which ultimately caused brain damage, including the cerebral white matter and deep grey matter[5]. Importantly, inflammation was increasingly implicated as a prominent component and a candidate factor of SVD[10]. Markers of inflammation were classified as systemic inflammation such as C-reactive protein, interleukin6, fibrinogen and vascular inflammation/endothelial dysfunction (e.g., homocysteine, von Willebrand factor, and Lp-PLA2)[11]. Existing studies indicated that systemic and vascular inflammation/endothelial dysfunction were differentially associated with different forms of SVD. Specifically, vascular inflammation was related to hypertensive arteriopathy-type SVD, whereas systemic inflammation was related to cerebral amyloid angiopathy (CAA)-type SVD. The most widely investigated markers of inflammation including C-reactive protein (CRP) and homocysteine. CRP was a sensitive but nonspecific marker of systemic inflammation. Homocysteine was thought to cause damage to the endothelium[12] and subsequently result in blood-brain barrier dysfunctions[13]. Associations between vascular clinical factors and SVD remained controversial. Hypertension, smoking, diabetes and sex were all proposed to be associated with SVD previously[14]. However, the conclusion was not only inconsistent in different studies[15] but also for different individual features of SVD[16, 17].

The total SVD burden combining 4 individual but closely correlated MRI features of SVD in one measure, including CMBs, lacunes, WMH and ePVS[5, 18], provided a complete estimate of the full impact of SVD in a simple way. The total SVD burden provided a more complete and pragmatic overall view of the impact of SVD on the neurological diseases that was better than considering only 1 or 2 individual features separately[19, 20].

No studies had specifically investigated dysphagia in patients with a single RSSI in the context of total SVD burden. We therefore sought to assess the frequency of PSD in patients with a MRI-confirmed single 
RSSI and to identify the association between the total SVD burden and PSD in these patients. Several clinical data were identified associated with the occurrence of PSD in patients with a single RSSI, including older age, higher stroke severity, higher CRP and fibrinogen levels. In addition, we identified that dysphagia in patients with a single recent small subcortical infarct resulted from severe small vascular disease, which was associated with systemic inflammation. This information might provide a new antiinflammatory treatment for post-stroke dysphagia in the future.

\section{Methods}

\subsection{Participants}

We identified all AIS patients in the medical system of our stroke database admitted to the stroke unit at First Affiliated Hospital of Soochow University between October 2017 and January 2019. Selection criteria were as follows: (1) diagnosis of AIS confirmed by diffusion-weighted MRI (DWI); (2) diagnosis for a single RSSI according to the STandards for Reportlng Vascular changes on nEuroimaging consensus (STRIVE) criteria[21] by two neuroimaging experts blinded to clinical data. Patients with the following were excluded: (1) multiple RSSIs or additional acute infarcts in other locations; (2) pre-existing dysphagia or concomitant diseases likely to cause dysphagia, including dementia; (3) concomitant brain hemorrhage; (4) brain tumors; (5) severe hepatic and renal dysfunction or end-stage severe disease. In a sample size calculation $N=221$, patients would yield a power of $80 \%$ to detect a statistically significant difference (alpha $=0.05$, two-sided). All patients were divided into two groups according to the following swallowing assessment: (1) patients with PSD; (2) patients with no PSD.

\subsection{Swallowing assessment}

The assessment of swallowing function was examined according to the water-swallowing test (WST) and volume-viscosity swallow test (V-VST), which were performed by a trained neurologist blinded to the clinical data. WST was performed using $30 \mathrm{ml}$ of water while sitting at a $90^{\circ}$ angle[22]. V-VST was assessed within the first 24 hours following admission before oral feeding and with gradually increased volumes from 5, 10 to $20 \mathrm{ml}$ and with different viscosities (thin liquid, nectar-like and spoon thick) in combination with a pulse-oximeter to evaluate both the efficacy and safety of swallowing function. Signs of impaired efficacy of swallowing include efficiency of labial seal, oral residue, fractional swallow and pharyngeal residue. Sign of impaired safety of swallowing include changes in voice quality, coughing and decrease in oxygen saturation $\left(\mathrm{SpO}_{2}\right) \geq 3 \%$ for $>1$ minute compared to baseline[23]. Patients who presented any sign of impaired efficacy and/or safety when swallowing were considered positive for PSD.

\subsection{Clinical data}

We extracted all the following variables: age, sex, systolic blood pressure, diastolic blood pressure, medical history (including hypertension, diabetes mellitus, atrial fibrillation, smoking and previous stroke) and clinical data on admission (including relevant laboratory indicators, stroke severity measured by NIHSS, thrombolytic treatment). The diagnosis of post-stroke pneumonia was identified by our treating 
team and defined based on $\geq 3$ of the following 6 features: (1) fever $\left(>38^{\circ} \mathrm{C}\right)$; (2) productive cough; (3) abnormal respiratory examination; (4) abnormal chest radiograph; (5) white blood cell count > 12000/ml; (6) isolation of a relevant pathogen and use of antibiotics.

\subsection{MRI acquisition}

All patients were scanned in a 3T MR scanner (MAGNETOM Skyra; Siemens Healthineers, Erlangen, Germany). The standard brain array coil was used for signal reception. The images obtained included transverse T1-weighted turbo spin-echo (TSE) images (repetition time (msec)/echo time (msec), 700/14; section thickness, $3 \mathrm{~mm}$; intersection gap, $0.5 \mathrm{~mm}$; field of view, $25 \mathrm{~cm}$; matrix, 384×336) and transverse, coronal and sagittal T2-weighted TSE images (repetition time (msec)/effective echo time (msec) 6,000/124; section thickness, $3 \mathrm{~mm}$; intersection gap, $0.3 \mathrm{~mm}$; field of view, $25 \mathrm{~cm}$; matrix, 384×336). DWI was obtained to calculate an apparent diffusion coefficient using a 2D echo planar imaging sequence with multiple b-value acquisitions $(0,100,800,1000$ and $1500 \mathrm{~s} / \mathrm{mm} 2)$, with the diffusion-sensitizing gradients applied along the $X, Y$ and $Z$ axes. MRI brain scans were obtained within 3 days after symptom onset for each participant admitted to the hospital. Brain lesions were localized according to hemisphere (left, right).

\subsection{MRI analysis}

All images were assessed by two neuroradiologist blinded to clinical information. In case of disagreement, a consensus meeting was held. A single RSSI was identified based on STRIVE criteria[21] and located to four brain lesions as follows: basal ganglia, thalamus, centrum semiovale and pons[24] (Fig. 2). Briefly, CMBs were defined on SWI as small ( $<5 \mathrm{~mm})$, homogeneous, rounded lesions of low signal intensity $[21,25]$. Lacunes were identified as asymptomatic rounded or ovoid hyperintense lesions in subcortical areas between 3 and $20 \mathrm{~mm}$ in diameter, of CSF signal intensity on T2 and Flair, with a hyperintense rim on FLAIR and no increased signal on DWI[26]. Deep and periventricular WMH were graded according to the Fazekas score from 0 to 3[27]. EPVS was defined as small ( $<3 \mathrm{~mm}$ ) punctate (if perpendicular to the plane of scan) and linear (if longitudinal) lesions in both BG and centrum semiovale regions with signal intensity equal to cerebrospinal fluid on $\mathrm{T} 1, \mathrm{~T} 2$ and flair sequence spaces without a hyperintense rim on FLAIR images[21].

\subsection{Total MRI-confirmed SVD burden}

We constructed the total MRI-confirmed SVD burden on an ordinal scale ranging from 0 to 4 by counting $4 \mathrm{MRI}$ features of SVD (CMBs, Lacunes, WMH and ePVS)[16]. The presence of each of the following items was awarded one point (Fig. 3): presence of lacunes and CMBs were defined as $\geq 1$ asymptomatic lacune or $\geq 1$ CMBs (1 point if present); moderate to extensive ( $\geq 11)$ PVS (1 point if present); presence of WMH was defined as either deep WMH (Fazekas score 2 or 3 ) or periventricular WMH (Fazekas score 3 ) (1 point if present)[28].

\subsection{Statistical analysis}


Values were presented as the mean \pm standard deviation (SD) and analysed using SPSS 20.0 software (SPSS, Inc., Chicago, IL, USA). Parametric data were analysed by Student's t-test and one-way ANOVA. Categorical data were conducted by Chi-squared test or Mann-Whitney test. Binary univariate and multivariate logistic regression analysis with simultaneous inclusion was applied to identify predictors of dysphagia and compare clinical outcomes in participants with and without dysphagia. Pearson correlations were conducted to analyse the relationships between markers of inflammation and the total SVD burden.

\section{Results}

\subsection{Patient characteristics}

A total of 308 patients fulfilled the inclusion criteria and were included in the study (Fig. 1). 54 (17.53\%) of them were with PSD. Demographic and clinical data of the study population and differences between dysphagia and nondysphagia patients with a single RSSI were displayed in Table 1. The groups significantly differed in age: patients with dysphagia were older than the nondysphagia patients (67.54 \pm 11.74 vs $61.00 \pm 13.06$ years, $\left.p=1.00 \times 10^{-3}\right)$. Patients in the nondysphagia group exhibited higher triglyceride $\left(1.67 \pm 1.00 \mathrm{vs} 1.33 \pm 0.51 \mathrm{mmol} / \mathrm{l}, \mathrm{p}<1.00 \times 10^{-3}\right)$ and higher uric acid $(312.56 \pm 91.35 \mathrm{vs}$ $282.17 \pm 80.91 \mu \mathrm{mol} / \mathrm{l}, \mathrm{p}=0.03$ ) levels compared with the dysphagia group. PSD patients exhibited higher score in NIHSS $\left(7.78 \pm 6.23\right.$ vs $\left.3.23 \pm 2.92, p<1.00 \times 10^{-3}\right)$. A significant difference was found between the groups that dysphagic patients exhibiting more post-stroke pneumonia $\left(44.40 \%\right.$ vs $14.96 \%, p<1.00 \times 10^{-}$ $\left.{ }^{3}\right)$. A significantly strong association was noted between both higher CRP $(62.96 \%$ vs $27.95 \%, p<$ $\left.1.00 \times 10^{-3}\right)$ and fibrinogen levels ( $3.18 \pm 0.96$ vs $\left.2.61 \pm 0.93, p<1.00 \times 10^{-3}\right)$. 
Table 1

Demographic and Clinical Data of Single-RSSI Patients with Dysphagia and Controls

\begin{tabular}{|c|c|c|c|c|}
\hline $\begin{array}{l}\text { Demographic and } \\
\text { Clinical Data }\end{array}$ & $\begin{array}{l}\text { Dysphagia } \\
(n=54)\end{array}$ & $\begin{array}{l}\text { Controls } \\
(n=254)\end{array}$ & $t / Z / \chi^{2}$ & $\mathrm{p}$ \\
\hline Age (years) & $\begin{array}{l}67.54 \pm 11.74,42.00- \\
91.00\end{array}$ & $\begin{array}{l}61.00 \pm 13.06,22.00- \\
89.00\end{array}$ & $\begin{array}{l}\mathrm{t}= \\
-3.40\end{array}$ & $\begin{array}{l}1.00 \times 10^{-} \\
3\end{array}$ \\
\hline Gender male/female & $37 / 17$ & $176 / 78$ & $\begin{array}{l}x^{2}= \\
0.01\end{array}$ & 0.91 \\
\hline $\begin{array}{l}\text { Systolic Blood Pressure } \\
(\mathrm{mmHg})\end{array}$ & $\begin{array}{l}152.57 \pm 24.87 \\
105.00-220.00\end{array}$ & $\begin{array}{l}147.44 \pm 21.40 \\
100.00-230.00\end{array}$ & $\begin{array}{l}t= \\
-1.55\end{array}$ & 0.12 \\
\hline $\begin{array}{l}\text { Diastolic Blood Pressure } \\
(\mathrm{mmHg})\end{array}$ & $\begin{array}{l}82.54 \pm 12.11,53.00- \\
111.00\end{array}$ & $\begin{array}{l}81.94 \pm 12.89,50.00- \\
131.00\end{array}$ & $\begin{array}{l}t= \\
-0.31\end{array}$ & 0.76 \\
\hline $\begin{array}{l}\text { History of Hypertension } \\
\text { yes/no }\end{array}$ & $40 / 14$ & $192 / 62$ & $\begin{array}{l}x^{2}= \\
0.06\end{array}$ & 0.81 \\
\hline $\begin{array}{l}\text { History of Diabetes } \\
\text { yes/no }\end{array}$ & $17 / 37$ & $75 / 179$ & $\begin{array}{l}\chi^{2}= \\
0.08\end{array}$ & 0.78 \\
\hline Smoking yes/no & $12 / 42$ & $68 / 186$ & $\begin{array}{l}x^{2}= \\
0.48\end{array}$ & 0.49 \\
\hline History of $\mathrm{AF}^{\dagger}$ yes/no & $4 / 50$ & $7 / 247$ & $\begin{array}{l}Z= \\
-1.67\end{array}$ & 0.11 \\
\hline Previous Stroke yes/no & $12 / 42$ & $34 / 220$ & $\begin{array}{l}x^{2}= \\
2.74\end{array}$ & 0.10 \\
\hline Triglyceride (mmol/L) & $\begin{array}{l}1.33 \pm 0.51 \\
0.49-2.55\end{array}$ & $\begin{array}{l}1.67 \pm 1.00 \\
0.38-9.11\end{array}$ & $\begin{array}{l}t= \\
3.68\end{array}$ & $\begin{array}{l}< \\
1.00 \times 10^{-}\end{array}$ \\
\hline $\begin{array}{l}\text { Total Cholesterol } \\
(\mathrm{mmol} / \mathrm{L})\end{array}$ & $\begin{array}{l}4.30 \pm 1.03 \\
1.51-6.33\end{array}$ & $\begin{array}{l}4.36 \pm 1.05 \\
1.94-9.90\end{array}$ & $\begin{array}{l}t= \\
0.38\end{array}$ & 0.70 \\
\hline
\end{tabular}

* Continuous data are shown as mean $\pm S D$, minimum and maximum values in patients with dysphagia and controls with statistical significance based on two sample T test. Categorical data differences in patients and controls are represented with statistical significance based on chi-squared test $\left(\chi^{2} \& p\right)$ or Fisher exact test $(Z \& p) . *: p<0.001$.

† AF refers to atrial fibrillation, LDLC refers to low density lipoprotein cholesterol, Higher CRP refers to C-reactive protein $\geq 3 \mathrm{mg} / \mathrm{l}$.

¥44 patients with dysphagia and 215 controls took part in Homocysteine tests, 37 patients with dysphagia and 196 controls took part in Hemoglobin A1c tests, while 17 patients with dysphagia and 68 controls attended Lp-PIA2 tests. 


\begin{tabular}{|c|c|c|c|c|}
\hline $\begin{array}{l}\text { Demographic and } \\
\text { Clinical Data }\end{array}$ & $\begin{array}{l}\text { Dysphagia } \\
(n=54)\end{array}$ & $\begin{array}{l}\text { Controls } \\
(n=254)\end{array}$ & $t / Z / \chi^{2}$ & $\mathbf{p}$ \\
\hline $\operatorname{LDLC}(\mathrm{mmol} / \mathrm{L})$ & $\begin{array}{l}2.62 \pm 0.94 \\
0.63-5.01\end{array}$ & $\begin{array}{l}2.65 \pm 0.91 \\
0.65-8.11\end{array}$ & $\begin{array}{l}t= \\
0.25\end{array}$ & 0.80 \\
\hline Creatinine $(\mu \mathrm{mol} / \mathrm{L})$ & $\begin{array}{l}67.78 \pm 13.99 \\
47.30-102.00\end{array}$ & $\begin{array}{l}70.24 \pm 21.53,33.20- \\
225.30\end{array}$ & $\begin{array}{l}\mathrm{t}= \\
0.80\end{array}$ & 0.42 \\
\hline Uric Acid $(\mu \mathrm{mol} / \mathrm{L})$ & $\begin{array}{l}282.17 \pm 80.91 \\
138.40-472.40\end{array}$ & $\begin{array}{l}312.56 \pm 91.35,92.50- \\
648.00\end{array}$ & $\begin{array}{l}t= \\
2.24\end{array}$ & 0.03 \\
\hline $\begin{array}{l}\text { Fasting Blood Glucose } \\
(\mu \mathrm{mol} / \mathrm{L})\end{array}$ & $\begin{array}{l}6.03 \pm 1.84 \\
3.92-12.76\end{array}$ & $\begin{array}{l}5.98 \pm 2.07 \\
3.34-19.60\end{array}$ & $\begin{array}{l}t= \\
3.78\end{array}$ & 0.88 \\
\hline Homocysteine $^{\ddagger}(\mu \mathrm{mol} / \mathrm{L})$ & $\begin{array}{l}14.13 \pm 9.12,6.20- \\
55.60\end{array}$ & $\begin{array}{l}12.84 \pm 8.67,3.40- \\
74.40\end{array}$ & $\begin{array}{l}t= \\
-0.89\end{array}$ & 0.38 \\
\hline Hemoglobin $\mathrm{A} 1 \mathrm{c}^{\ddagger}(\%)$ & $\begin{array}{l}7.08 \pm 1.79 \\
5.20-12.10\end{array}$ & $\begin{array}{l}6.72 \pm 1.67 \\
4.90-15.10\end{array}$ & $\begin{array}{l}t= \\
-1.20\end{array}$ & 0.23 \\
\hline NIH Stroke Scale & $\begin{array}{l}7.78 \pm 6.23 \\
0.00-36.00\end{array}$ & $\begin{array}{l}3.23 \pm 2.92 \\
0.00-15.00\end{array}$ & $\begin{array}{l}t= \\
-8.18\end{array}$ & $\begin{array}{l}< \\
1.00 \times 10^{-} \\
3 *\end{array}$ \\
\hline Higher $\mathrm{CRP}^{+}$ & $34 / 20$ & $71 / 183$ & $\begin{array}{l}x^{2}= \\
24.29\end{array}$ & $\begin{array}{l}< \\
1.00 \times 10^{-} \\
3 \star\end{array}$ \\
\hline Fibrinogen $(\mathrm{g} / \mathrm{l})$ & $\begin{array}{l}3.18 \pm 0.96 \\
0.75-6.18\end{array}$ & $\begin{array}{l}2.61 \pm 0.93 \\
0.75-6.77\end{array}$ & $\begin{array}{l}t= \\
-4.06\end{array}$ & $\begin{array}{l}< \\
1.00 \times 10^{-} \\
3 \star\end{array}$ \\
\hline Lp-PIA2 $2^{\ddagger}(\mathrm{ug} / \mathrm{l})$ & $\begin{array}{l}139.29 \pm 56.82,63.81- \\
311.64\end{array}$ & $\begin{array}{l}157.36 \pm 140.79 \\
56.04-800.00\end{array}$ & $\begin{array}{l}\mathrm{t}= \\
0.52\end{array}$ & 0.61 \\
\hline Thrombolytic yes/no & $12 / 42$ & $53 / 201$ & $\begin{array}{l}\chi^{2}= \\
0.05\end{array}$ & 0.82 \\
\hline
\end{tabular}

* Continuous data are shown as mean $\pm S D$, minimum and maximum values in patients with dysphagia and controls with statistical significance based on two sample T test. Categorical data differences in patients and controls are represented with statistical significance based on chi-squared test $\left(\chi^{2} \& p\right)$ or Fisher exact test $(Z \& p) . *: p<0.001$.

† AF refers to atrial fibrillation, LDLC refers to low density lipoprotein cholesterol, Higher CRP refers to C-reactive protein $\geq 3 \mathrm{mg} / \mathrm{l}$.

¥44 patients with dysphagia and 215 controls took part in Homocysteine tests, 37 patients with dysphagia and 196 controls took part in Hemoglobin A1c tests, while 17 patients with dysphagia and 68 controls attended Lp-PIA2 tests. 


\begin{tabular}{|c|c|c|c|c|}
\hline $\begin{array}{l}\text { Demographic and } \\
\text { Clinical Data }\end{array}$ & $\begin{array}{l}\text { Dysphagia } \\
(\mathrm{n}=54)\end{array}$ & $\begin{array}{l}\text { Controls } \\
(n=254)\end{array}$ & $\mathrm{t} / \mathrm{Z} / \mathrm{X}^{2}$ & $p$ \\
\hline $\begin{array}{l}\text { Post-stroke pneumonia } \\
\text { yes/no }\end{array}$ & $24 / 30$ & $38 / 216$ & $\begin{array}{l}x^{2}= \\
24.08\end{array}$ & $\begin{array}{l}< \\
1.00 \times 10^{-} \\
3 *\end{array}$ \\
\hline \multicolumn{5}{|c|}{$\begin{array}{l}\text { * Continuous data are shown as mean } \pm S D \text {, minimum and maximum values in patients with } \\
\text { dysphagia and controls with statistical significance based on two sample T test. Categorical data } \\
\text { differences in patients and controls are represented with statistical significance based on chi-squared } \\
\text { test }\left(\chi^{2} \& p\right) \text { or Fisher exact test }(Z \& p) . *: p<0.001 \text {. }\end{array}$} \\
\hline \multicolumn{5}{|c|}{$\begin{array}{l}\text { †AF refers to atrial fibrillation, LDLC refers to low density lipoprotein cholesterol, Higher CRP refers to } \\
\text { C-reactive protein } \geq 3 \mathrm{mg} / \mathrm{l} \text {. }\end{array}$} \\
\hline \multicolumn{5}{|c|}{$\begin{array}{l}\ddagger 44 \text { patients with dysphagia and } 215 \text { controls took part in Homocysteine tests, } 37 \text { patients with } \\
\text { dysphagia and } 196 \text { controls took part in Hemoglobin A1c tests, while } 17 \text { patients with dysphagia and } \\
68 \text { controls attended Lp-PIA2 tests. }\end{array}$} \\
\hline
\end{tabular}

\subsection{Associations between Radiological Factors and PSD}

The majority of single RSSIs were located in the basal ganglia $(n=142,46.10 \%)$ followed by pons $(n=70$, $22.73 \%)$, centrum semiovale $(n=60,19.48 \%)$, and thalamus $(n=36,11.69 \%)$. Neuroimaging examples of prespecified single RSSI locations were provided in Fig. 2. Given that single RSSI locations exhibited significant differences between PSD and non-PSD patients $(p=0.04)$, we further investigated the associations of single RSSI locations and dysphagia as shown in Table 2. Patients with RSSI located in the pons suffered from dysphagia more often $\left(O R=2.95, p=0.50 \times 10^{-3}\right)$, whereas no significant differences were noted between patients with RSSI located in the basal ganglia, thalamus and centrum semiovale $(O R=0.91, p=0.75 ; O R=0.00, p=1.00 ; O R=0.47, p=0.23$, respectively). No associations were noted between a single RSSI side and dysphagia (left, $57.41 \%$ vs $53.15 \% ; p=0.57$ ). All four concomitant MRI findings (including lacunes, perivascular spaces, WMH Fazekas 2-3 and microbleeds) were significantly different between single RSSI patients with and without dysphagia in Table 2. 
Table 2

Radiological Data of Single-RSSI Patients with Dysphagia and Controls

\begin{tabular}{|c|c|c|c|c|}
\hline Variable & $\begin{array}{l}\text { Dysphagia } \\
(n=54)\end{array}$ & $\begin{array}{l}\text { Controls } \\
(n=254)\end{array}$ & $\chi^{2} / z$ & $\mathbf{p}$ \\
\hline \multicolumn{5}{|l|}{ Single-RSSI Location, $\mathrm{n}(\%)$} \\
\hline Basal Ganglia & $23(42.59)$ & $119(46.85)$ & $x^{2}=0.10$ & 0.75 \\
\hline Thalamus & $1(1.85)$ & $35(13.78)$ & $z=0$ & 1.00 \\
\hline Centrum Semiovale & $8(14.82)$ & $52(20.47)$ & $\chi^{2}=1.47$ & 0.23 \\
\hline Pons & $22(40.74)$ & $48(18.90)$ & $\chi^{2}=12.10$ & $0.50 \times 10^{-3}$ \\
\hline Lesioned Hemi Left, n (\%) & $31(57.41)$ & $135(53.15)$ & $x^{2}=0.32$ & 0.57 \\
\hline \multicolumn{5}{|c|}{ Concomitant MRI Findings, n (\%) } \\
\hline Lacunes & $44(81.48)$ & $130(51.18)$ & $\chi^{2}=16.64$ & $<1.00 \times 10^{-3 *}$ \\
\hline Perivascular Spaces & $36(66.67)$ & $77(30.31)$ & $\chi^{2}=25.34$ & $<1.00 \times 10^{-3 *}$ \\
\hline WMH Fazekas 2-3† & $26(48.15)$ & $65(25.59)$ & $\chi^{2}=10.89$ & $1.00 \times 10^{-3}$ \\
\hline Microbleeds & $16(29.63)$ & 17(6.69) & $\chi^{2}=24.49$ & $<1.00 \times 10^{-3 *}$ \\
\hline \multicolumn{5}{|c|}{$\begin{array}{l}\text { * Categorical data differences in patients and controls are represented with statistical significance } \\
\text { based on chi-squared test }\left(\chi^{2} \& p\right) \text { or Fisher exact test }(Z \& p) . *: p<0.001 .\end{array}$} \\
\hline \multicolumn{5}{|c|}{ † WMH refers to white matter hyperintensities. } \\
\hline \multicolumn{5}{|c|}{$\begin{array}{l}\text { * Patients located in pons suffered from dysphagia more often }\left(\mathrm{OR}=2.95, \mathrm{p}=0.50 \times 10^{-3}\right) \text {, therewere } \\
\text { no significant difference between patients located in the basal ganglia, thalamus and centrum } \\
\text { semiovale (OR = } 0.91, p=0.75 ; \mathrm{OR}=0.00, p=1.00 ; \mathrm{OR}=0.47, \mathrm{p}=0.23 \text {, separately). There were no } \\
\text { associations between a single RSSI side and dysphagia (left, } 57.41 \% \text { vs } 53.15 \% ; \mathrm{p}=0.57) \text {. All four } \\
\text { concomitant MRI findings (including Lacunes, Perivascular spaces, WMH Fazekas } 2-3 \text { and } \\
\text { Microbleeds) were signifcantly different between single RSSI patients with and without dysphagia. }\end{array}$} \\
\hline
\end{tabular}

\subsection{Associations Between total SVD burden and PSD}

Among the single RSSI patients who scored 1, most (62.61\%) had lacunes followed by ePVS $(26.09 \%)$, CMBs (6.09\%) and WMH (5.21\%) (Table 3). Among patients who scored 2, all possible combinations were present, with combination of WMH + lacunes (34.25\%) and ePVS + lacunes (34.25\%) were predominant. Among patients who scored 3 , all possible combinations were present, with $\mathrm{PVS}+\mathrm{WMH}+$ lacunes $(67.57 \%)$ was most common. Dysphagic patients had higher ratings of total SVD burden compared with nondysphagic patients (Table 3; $p<1.00 \times 10^{-3}$ ). In multivariate logistic regression models for patients with dysphagia, total SVD burden was identified as an independent risk factor for PSD $(O R=2.27,[1.56$, 3.31], $p=1.75 \times 10^{-5}$; Table 4). 
Table 3

Total SVD Score Values for Single-RSSI Patients with Dysphagia and Controls

\begin{tabular}{|c|c|c|c|}
\hline Total SVD Score & $\begin{array}{l}\text { All Patients } \\
(n=308)\end{array}$ & $\begin{array}{l}\text { Dysphagia } \\
(n=54)\end{array}$ & $\begin{array}{l}\text { Controls } \\
(n=254)\end{array}$ \\
\hline 0 & $73(23.70)$ & $6(11.11)$ & $67(26.38)$ \\
\hline 1 & 115(37.34) & $7(12.96)$ & $108(42.52)$ \\
\hline 2 & $73(23.70)$ & $16(29.63)$ & $57(22.44)$ \\
\hline 3 & $37(12.01)$ & $17(31.48)$ & $20(7.87)$ \\
\hline 4 & $10(3.25)$ & $8(14.82)$ & $2(0.79)$ \\
\hline \multicolumn{4}{|c|}{$\begin{array}{l}\text { * SVD refers to small vessel disease. On brain magnetic resonance imaging, we independently rated } \\
\text { the presence of cerebral microbleeds, lacunes, white matter hyperintensities and enlarged perivascula } \\
\text { spaces. The presence of each SVD feature was summed in the total SVD score ranging from } 0-4 \text {. } \\
\text { Data presented as number (\%). Mann-Whitney test Dysphagia vs Controls in Single-RSSI Patients, Z= } \\
-6.29, p<1.00 \times 10^{-3} \text {. }\end{array}$} \\
\hline
\end{tabular}

Table 4

Multivariable Logistic Regression Model for Predicting Patients with Dysphagia

\begin{tabular}{|lllll|}
\hline Variables & Odds Ratio & $95 \%$ Cl & t & P value \\
\hline & 1.02 & $0.99,1.05$ & 1.16 & 0.25 \\
\cline { 2 - 6 } & & & & \\
\hline Age & 1.59 & $0.70,3.63$ & 1.11 & 0.26 \\
\hline History of Hypertension & 0.41 & $0.18,0.95$ & -2.08 & 0.04 \\
\hline NIH Stroke Scale & 1.25 & $1.13,1.37$ & 4.46 & $8.12 \times 10^{-6 * *}$ \\
\hline Higher CRP ${ }^{\dagger}$ & 1.66 & $0.77,3.59$ & 1.29 & 0.20 \\
\hline Fibrinogen (g/l) & 1.19 & $0.83,1.71$ & 0.95 & 0.34 \\
\hline SVD burden ${ }^{\dagger}$ & 2.27 & $1.56,3.31$ & 4.30 & $1.75 \times 10^{-5 * *}$ \\
\hline T Higher CRP refers to C-reactive protein $\geq 3 \mathrm{mg} /$ l; SVD refers to small vessel disease. \\
\hline
\end{tabular}

\subsection{Correlations between markers of inflammation and total SVD burden}

Table 5 presented the correlations between markers of inflammation and total SVD burden in single RSSI patients. The CRP and fibrinogen level were positively correlated with total SVD burden score $(r=0.19, p=$ $1.00 \times 10^{-3} ; r=0.21, p=3.00 \times 10^{-4}$, respectively, Fig. 4). No associations between homocysteine or LpPIA2 levels and total SVD burden score were observed ( $r=0.08, p=0.22 ; r=0.11, p=0.30$, respectively). 
Table 5

Correlations between markers of inflammation and total SVD burden in single-RSSI patients

\begin{tabular}{|c|c|c|}
\hline Variables & SVD & \\
\hline & $\mathbf{r}$ & $P$ value \\
\hline CRP† & 0.19 & $1.00 \times 10^{-3}$ \\
\hline Fibrinogen $(\mathrm{g} / \mathrm{l})$ & 0.21 & $3.00 \times 10^{-4}$ \\
\hline Homocysteine (umol/l) $\ddagger$ & 0.08 & 0.22 \\
\hline Lp-PIA2 (ug/l) $\ddagger$ & 0.11 & 0.30 \\
\hline † CRP refers to $\mathrm{C}$-reactive & & \\
\hline $\begin{array}{l}\text { ‡ } 44 \text { patients with dyspha } \\
\text { dysphagia and } 68 \text { control }\end{array}$ & Homo & ests, while 1 \\
\hline
\end{tabular}

\section{Discussion}

This study showed two major findings in AIS patients with a single RSSI: (1) Clinical risk factors of PSD with a single RSSI were identified: older age, higher stroke severity (NIHSS), elevated CRP and fibrinogen levels. (2) Dysphagia in single RSSI patients resulted from severe small vascular disease, which was associated with systemic inflammation.

PSD was common in hospitalized patients and associated with increased mortality and comorbidities, including post-stroke pneumonia, malnutrition, dehydration and mortality[29]. Among AIS patients, 50$80 \%$ had trouble with swallowing, especially during the first week after their stroke[30]. The importance for screening of PSD had been emphasized at both international symposiums and in clinical audit reports. In the American Heart Association/American Stroke Association 2019 guidelines for the Early Management of AIS, dysphagia screening was effective in identifying patients at increased risk for aspiration, and these guidelines had strength/class of recommendation I (strong benefit to risk ratio) but C-LD level of evidence (limited data)[31]. The prevalence of PSD (17.53\%) among AIS patients with RSSI in our study was consistent with other investigators given that $20 \%$ suffered from PSD. We also confirmed previous findings demonstrating that patients with PSD carried a high risk of post-stroke pneumonia (44.44\%).

Prior studies using different methods demonstrated that bilateral activation of the sensorimotor cortex[32] and a bilateral redistribution of swallowing networks after stroke[33]. In fact, many structures associated with swallowing were located in subcortical regions, such as corticonuclear tracts, periventricular connections of cortical regions and extrapyramidal pathways[8]. Damage to subcortical 
lesions on one hemisphere might be completely compensated by the contralateral side. However, studies identified that almost one-quarter of patients with RSSI had dysphagia. We hypothesized that PSD may not only be disrupted by a single RSSI but also by concomitant cerebrovascular lesions. Widely distributed morphological changes from SVD may have a strong effect[34]. Studies investigating RSSI patients in the context of SVD were largely unknown[35].

SVD was a common condition that affected small cerebral arterioles, capillaries, and venules. This condition had long been implicated with clinical manifestations ranging from clinically silent to focal neurological dysfunction, such as stroke, and even to global neurological symptoms and dementia[36]. Features of SVD on MRI included RSSI, WMH, lacunes, ePVS, CMBs and atrophy[37]. Terminology for these lesions have highly varied between studies[38,39]. Neuroimaging consensus standards for classification of SVD were first proposed by the US National Institute of Neurological Disorders and Stroke and the Canadian Stroke Network[40]. The STandards for Reportlng Vascular changes on nEuroimaging (STRIVE) consensus defined clear, rigorous, evidence-based, and easy-to-apply terminology for SVD, which provided a consistent approach to neuroimaging[41].

Our study identified demographic and clinical factors that were associated with PSD to identify those RSSI patients at an early stage with a greater risk of PSD. Previous research $[30,42,43]$ had proposed various risk factors of PSD. Age, stroke severity and larger infarctions were consistently considered to be independent predictors for PSD [31, 44]. In addition to the brain stem, both cortical and subcortical regions played an important role in swallowing[3]. To date, there was no clear conclusion about the relationship between brain lesions locations and the occurrence of PSD. However, almost none of these studies particularly focused on dysphagia in patients with RSSI.

Dysphagia in subcortical stroke may be caused by damage to swallowing pathways, including corticonuclear tracts, extrapyramidal pathways and periventricular connections of cortical regions. Prior studies investigating larger subcortical strokes reported an impact of acute lesion locations on the occurrence and severity of PSD but rarely explored combined effects of acute and pre-existing cerebrovascular lesions on dysphagia[45]. A retrospective study revealed that PSD was closely linked to bilateral pyramidal tract damage by both acute RSSI and pre-existing contralateral cerebrovascular lesions (lacunes and severe WMH)[1]. Therefore, widely distributed morphological changes caused by SVD may additionally contribute to PSD especially for RSSI patients.

Little information was known about the pathogenesis of SVD and how this process resulted in neurological disease. However, the process had been attributed to proximal perforating arteriolar atheroma, lipohyalinosis, or fibrinoid necrosis[46], which were thought largely to result as a consequence of hypertension or vasospasm or recently to result from inflammation. Proximal perforating arteriolar atheroma was associated with a larger infarct of the basal ganglia and more likely to be progressive stroke[47]. Lipohyalinosis was thought to be accompanied with additional features of SVD, such as WMH and lacunes[48]. Only a few acute lacunar infarcts, especially basal ganglia lesions, were caused by emboli. 
At present, there were no consistent conclusions about the relationship between systemic inflammation and SVD. Nevertheless, longitudinal investigations demonstrated that systemic inflammation, especially if the inflammation was sustained in the long term, promoted and predicted SVD progression[11]. The Atherosclerosis Risk in Communities study identified that a sustainable elevated level of CRP during midlife highly increased the risk of SVD after 20 years[49]. The existing literature revealed strong associations between SVD and markers of vascular inflammation rather than systemic inflammation in AIS patients, suggesting that the vascular inflammation/endothelial dysfunction and alterations to bloodbrain barrier may be the driving force behind SVD[50]. A small number of patients with Lp-PIA2 data may account for the failure to demonstrate the association with dysphagia.

An important difference between our study and those of others was that we focused on RSSI patients and explored relationship between pre-existing SVD and PSD. In addition, the total MRI burden score of SVD we used provided a more complete overall view of the pre-existing SVD than the individual features separately. Several limitations needed to be further addressed. First, both WST and V-VST were assessed using bedside screening tests. Although V-VST had been shown to be a well-validated clinical instrument with high sensitivity and specificity, instrumental testing, such as videofluoroscopic or flexible endoscopic evaluation of swallowing, might have aided in detection with higher precision and yielded higher rates of PSD. Second, further analysis of the various factors influencing the associations between inflammation and SVD (e.g., gender, ethnicity, APOE genotype, duration of inflammation) should be further assessed.

\section{Conclusions}

In conclusion, this study showed that dysphagia occurred in approximately $20 \%$ of AIS patients with a single RSSI. Possible clinical risk factors of PSD were identified: older age, higher stroke severity (NIHSS), elevated levels of CRP and fibrinogen. Dysphagia in patients with a single RSSI resulted from severe small vascular disease, which was associated with systemic inflammation. This information might provide a new anti-inflammatory treatment for post-stroke dysphagia in the future.

\section{Abbreviations}

PSD, post-stroke dysphagia; AIS, acute ischemic stroke; NIHSS, National Institutes of Health Stroke Scale; WST, water-swallowing test; V-VST, volume-viscosity swallow test; MRI, magnetic resonance imaging; SVD, small vessel disease; RSSI, recent small subcortical infarct; CRP, C-reactive protein.

\section{Declarations}

\section{Acknowledgments}

We would like to sincerely thank the Department of Neurology of The First Affiliated Hospital of Soochow University (Suzhou, China) for their support.

\section{Authors' contributions}


L.L. Zhang and X. Tang conceived the research and wrote the main manuscript text. Y.D. Li and D.X Ding participated in the recruitment of the sample population. J.H Zhu, Y. Zhou and S.S Diao acquired the data, analyzed the results. Y. Kong and X.Y. Cai helped in interpreted the results and revised the article. Y. Yao and Q. Fang guided the process, interpreted the results and revised the article. All authors read and approved the manuscript. The author(s) read and approved the final manuscript.

\section{Funding}

This work was supported by National Key R\&D Program of China (no. 2017YFC0114300 Qi Fang), Shanghai Sailing Program (no. 17YF142600 Ye Yao), Startup Foundation of School of Public Health (no. IDF201360/009, Ye Yao), Fudan University (no. KBH2306002, Ye Yao), the National Natural Science Foundation of China (no. 82001125 Xiang Tang) and Natural Science Foundation of Jiangsu Province (no. BK20180201 Xiang Tang).

\section{Availability of data and materials}

The data that supported the findings of this study were available from the corresponding author upon reasonable request.

\section{Ethics approval and consent to participate}

The First Affiliated Hospital of Soochow University ethics committee approved the present study, with all relevant guidelines and regulations being observed. All patients and/or their legal guardians provided informed consent.

\section{Consent for publication}

Not applicable.

\section{Competing interests}

The authors declared that they had no conflict of interest.

\section{References}

1. Fandler S, Gattringer T, Pinter D, Pirpamer L, Borsodi F, Eppinger S, et al. Dysphagia in supratentorial recent small subcortical infarcts results from bilateral pyramidal tract damage. International journal of stroke: official journal of the International Stroke Society. 2018;13 8:815-9; doi: 10.1177/1747493018778141.

2. Arnold M, Liesirova K, Broeg-Morvay A, Meisterernst J, Schlager M, Mono ML, et al. Dysphagia in Acute Stroke: Incidence, Burden and Impact on Clinical Outcome. PloS one. 2016;11 2:e0148424; doi: 10.1371/journal.pone.0148424. 
3. Wilmskoetter J, Bonilha L, Martin-Harris B, Elm JJ, Horn J, Bonilha HS. Mapping acute lesion locations to physiological swallow impairments after stroke. Neurolmage Clinical. 2019;22:101685; doi: 10.1016/j.nicl.2019.101685.

4. Fandler S, Gattringer T, Eppinger S, Doppelhofer K, Pinter D, Niederkorn K, et al. Frequency and Predictors of Dysphagia in Patients With Recent Small Subcortical Infarcts. Stroke. 2017;48 1:213-5; doi: 10.1161/STROKEAHA.116.015625.

5. Pantoni L. Cerebral small vessel disease: from pathogenesis and clinical characteristics to therapeutic challenges. The Lancet Neurology. 2010;9 7:689-701; doi: 10.1016/S14744422(10)70104-6.

6. Del Bene A, Makin SD, Doubal FN, Inzitari D, Wardlaw JM. Variation in risk factors for recent small subcortical infarcts with infarct size, shape, and location. Stroke. 2013;44 11:3000-6; doi: 10.1161/STROKEAHA.113.002227.

7. Daniels SK, Foundas AL. Lesion localization in acute stroke patients with risk of aspiration. Journal of neuroimaging: official journal of the American Society of Neuroimaging. 1999;9 2:91-8; doi: 10.1111/jon19999291.

8. Ertekin C, Aydogdu I, Tarlaci S, Turman AB, Kiylioglu N. Mechanisms of dysphagia in suprabulbar palsy with lacunar infarct. Stroke. 2000;31 6:1370-6; doi: 10.1161/01.str.31.6.1370.

9. Hilal S, Ikram MA, Verbeek MM, Franco OH, Stoops E, Vanderstichele H, et al. C-Reactive Protein, Plasma Amyloid-beta Levels, and Their Interaction With Magnetic Resonance Imaging Markers. Stroke. 2018;49 11:2692-8; doi: 10.1161/STROKEAHA.118.022317.

10. Abbott NJ. Inflammatory mediators and modulation of blood-brain barrier permeability. Cellular and molecular neurobiology. 2000;20 2:131 - 47; doi: 10.1023/a:1007074420772.

11. Low A, Mak E, Rowe JB, Markus HS, O'Brien JT. Inflammation and cerebral small vessel disease: A systematic review. Ageing research reviews. 2019;53:100916; doi: 10.1016/j.arr.2019.100916.

12. Pang X, Liu J, Zhao J, Mao J, Zhang X, Feng L, et al. Homocysteine induces the expression of Creactive protein via NMDAr-ROS-MAPK-NF-kappaB signal pathway in rat vascular smooth muscle cells. Atherosclerosis. 2014;236 1:73-81; doi: 10.1016/j.atherosclerosis.2014.06.021.

13. Suidan GL, Brill A, De Meyer SF, Voorhees JR, Cifuni SM, Cabral JE, et al. Endothelial Von Willebrand factor promotes blood-brain barrier flexibility and provides protection from hypoxia and seizures in mice. Arteriosclerosis, thrombosis, and vascular biology. 2013;33 9:2112-20; doi:

10.1161/ATVBAHA.113.301362.

14. Poels MM, Vernooij MW, Ikram MA, Hofman A, Krestin GP, van der Lugt A, et al. Prevalence and risk factors of cerebral microbleeds: an update of the Rotterdam scan study. Stroke. 2010;41 10 Suppl:S103-6; doi: 10.1161/STROKEAHA.110.595181.

15. Nakamori M, Hosomi N, Imamura E, Matsushima H, Maetani Y, Yoshida M, et al. Association between stroke lesions and videofluoroscopic findings in acute stroke patients. J Neurol. 2020; doi: 10.1007/s00415-020-10244-4. 
16. Klarenbeek P, van Oostenbrugge RJ, Rouhl RP, Knottnerus IL, Staals J. Ambulatory blood pressure in patients with lacunar stroke: association with total MRI burden of cerebral small vessel disease. Stroke. 2013;44 11:2995-9; doi: 10.1161/STROKEAHA.113.002545.

17. Wardlaw JM, Smith C, Dichgans M. Mechanisms of sporadic cerebral small vessel disease: insights from neuroimaging. The Lancet Neurology. 2013;12 5:483-97; doi: 10.1016/S1474-4422(13)700607.

18. Martino R, Foley N, Bhogal S, Diamant N, Speechley M, Teasell R. Dysphagia after stroke: incidence, diagnosis, and pulmonary complications. Stroke. 2005;36 12:2756-63; doi:

10.1161/01.STR.0000190056.76543.eb.

19. Xiao L, Lan W, Sun W, Dai Q, Xiong Y, Li L, et al. Chronic Kidney Disease in Patients With Lacunar Stroke: Association With Enlarged Perivascular Spaces and Total Magnetic Resonance Imaging Burden of Cerebral Small Vessel Disease. Stroke. 2015;46 8:2081-6; doi:

10.1161/STROKEAHA.114.008155.

20. Charidimou A, Martinez-Ramirez S, Reijmer YD, Oliveira-Filho J, Lauer A, Roongpiboonsopit D, et al. Total Magnetic Resonance Imaging Burden of Small Vessel Disease in Cerebral Amyloid Angiopathy: An Imaging-Pathologic Study of Concept Validation. JAMA neurology. 2016;73 8:994-1001; doi: 10.1001/jamaneurol.2016.0832.

21. Wardlaw JM, Smith EE, Biessels GJ, Cordonnier C, Fazekas F, Frayne R, et al. Neuroimaging standards for research into small vessel disease and its contribution to ageing and neurodegeneration. The Lancet Neurology. 2013;12 8:822-38; doi: 10.1016/S1474-4422(13)701248.

22. Osawa A, Maeshima S, Tanahashi N. Water-swallowing test: screening for aspiration in stroke patients. Cerebrovascular diseases. 2013;35 3:276-81; doi: 10.1159/000348683.

23. Rofes L, Muriana D, Palomeras E, Vilardell N, Palomera E, Alvarez-Berdugo D, et al. Prevalence, risk factors and complications of oropharyngeal dysphagia in stroke patients: A cohort study. Neurogastroenterology and motility: the official journal of the European Gastrointestinal Motility Society. 2018:e13338; doi: 10.1111/nmo.13338.

24. Ouriel K, Fowl RJ, Davies MG, Forbes TL, Gambhir RP, Morales JP, et al. Reporting standards for adverse events after medical device use in the peripheral vascular system. Journal of vascular surgery. 2013;58 3:776-86; doi: 10.1016/j.jvs.2013.06.059.

25. Greenberg SM, Vernooij MW, Cordonnier C, Viswanathan A, Al-Shahi Salman R, Warach S, et al. Cerebral microbleeds: a guide to detection and interpretation. The Lancet Neurology. 2009;8 2:16574; doi: 10.1016/S1474-4422(09)70013-4.

26. Huijts M, Duits A, van Oostenbrugge RJ, Kroon AA, de Leeuw PW, Staals J. Accumulation of MRI Markers of Cerebral Small Vessel Disease is Associated with Decreased Cognitive Function. A Study in First-Ever Lacunar Stroke and Hypertensive Patients. Frontiers in aging neuroscience. 2013;5:72; doi: 10.3389/fnagi.2013.00072. 
27. Fazekas F, Kleinert R, Offenbacher H, Schmidt R, Kleinert G, Payer F, et al. Pathologic correlates of incidental MRI white matter signal hyperintensities. Neurology. 1993;43 9:1683-9; doi: 10.1212/wnl.43.9.1683.

28. Vernooij MW, van der Lugt A, Ikram MA, Wielopolski PA, Niessen WJ, Hofman A, et al. Prevalence and risk factors of cerebral microbleeds: the Rotterdam Scan Study. Neurology. 2008;70 14:1208-14; doi: 10.1212/01.wnl.0000307750.41970.d9.

29. Benjamin EJ, Blaha MJ, Chiuve SE, Cushman M, Das SR, Deo R, et al. Heart Disease and Stroke Statistics-2017 Update: A Report From the American Heart Association. Circulation. 2017;135 10:e146-e603; doi: 10.1161/CIR.0000000000000485.

30. Suntrup-Krueger S, Kemmling A, Warnecke T, Hamacher C, Oelenberg S, Niederstadt T, et al. The impact of lesion location on dysphagia incidence, pattern and complications in acute stroke. Part 2: Oropharyngeal residue, swallow and cough response, and pneumonia. European journal of neurology. 2017;24 6:867-74; doi: 10.1111/ene.13307.

31. Powers WJ, Rabinstein AA, Ackerson T, Adeoye OM, Bambakidis NC, Becker K, et al. Guidelines for the Early Management of Patients With Acute Ischemic Stroke: 2019 Update to the 2018 Guidelines for the Early Management of Acute Ischemic Stroke: A Guideline for Healthcare Professionals From the American Heart Association/American Stroke Association. Stroke. 2019;50 12:e344-e418; doi: 10.1161/STR.0000000000000211.

32. Dziewas $R$, Soros $P$, Ishii $R$, Chau $W$, Henningsen $H$, Ringelstein $E B$, et al. Neuroimaging evidence for cortical involvement in the preparation and in the act of swallowing. Neurolmage. 2003;20 1:135-44; doi: 10.1016/s1053-8119(03)00285-4.

33. Li S, Ma Z, Tu S, Zhou M, Chen S, Guo Z, et al. Altered resting-state functional and white matter tract connectivity in stroke patients with dysphagia. Neurorehabilitation and neural repair. 2014;28 3:26072; doi: $10.1177 / 1545968313508227$.

34. Titsworth WL, Abram J, Fullerton A, Hester J, Guin P, Waters MF, et al. Prospective quality initiative to maximize dysphagia screening reduces hospital-acquired pneumonia prevalence in patients with stroke. Stroke. 2013;44 11:3154-60; doi: 10.1161/STROKEAHA.111.000204.

35. Cola MG, Daniels SK, Corey DM, Lemen LC, Romero M, Foundas AL. Relevance of subcortical stroke in dysphagia. Stroke. 2010;41 3:482-6; doi: 10.1161/STROKEAHA.109.566133.

36. Vemuri P, Lesnick TG, Przybelski SA, Knopman DS, Preboske GM, Kantarci K, et al. Vascular and amyloid pathologies are independent predictors of cognitive decline in normal elderly. Brain: a journal of neurology. 2015;138 Pt 3:761 - 71; doi: 10.1093/brain/awu393.

37. Staals J, Booth T, Morris Z, Bastin ME, Gow AJ, Corley J, et al. Total MRI load of cerebral small vessel disease and cognitive ability in older people. Neurobiology of aging. 2015;36 10:2806-11; doi: 10.1016/j.neurobiolaging.2015.06.024.

38. Potter GM, Marlborough FJ, Wardlaw JM. Wide variation in definition, detection, and description of lacunar lesions on imaging. Stroke. 2011;42 2:359-66; doi: 10.1161/STROKEAHA.110.594754. 
39. Zhu YC, Dufouil C, Tzourio C, Chabriat H. Silent brain infarcts: a review of MRI diagnostic criteria. Stroke. 2011;42 4:1140-5; doi: 10.1161/STROKEAHA.110.600114.

40. Hachinski V, ladecola C, Petersen RC, Breteler MM, Nyenhuis DL, Black SE, et al. National Institute of Neurological Disorders and Stroke-Canadian Stroke Network vascular cognitive impairment harmonization standards. Stroke. 2006;37 9:2220-41; doi: 10.1161/01.STR.0000237236.88823.47.

41. Flowers HL, Skoretz SA, Streiner DL, Silver FL, Martino R. MRI-based neuroanatomical predictors of dysphagia after acute ischemic stroke: a systematic review and meta-analysis. Cerebrovascular diseases. 2011;32 1:1-10; doi: 10.1159/000324940.

42. Smith EE, Kent DM, Bulsara KR, Leung LY, Lichtman JH, Reeves MJ, et al. Effect of Dysphagia Screening Strategies on Clinical Outcomes After Stroke: A Systematic Review for the 2018 Guidelines for the Early Management of Patients With Acute Ischemic Stroke. Stroke. 2018;49 3:e123-e8; doi: 10.1161/STR.0000000000000159.

43. Lapa S, Luger S, Pfeilschifter W, Henke C, Wagner M, Foerch C. Predictors of Dysphagia in Acute Pontine Infarction. Stroke. 2017;48 5:1397-9; doi: 10.1161/STROKEAHA.116.015045.

44. Joundi RA, Martino R, Saposnik G, Giannakeas V, Fang J, Kapral MK. Predictors and Outcomes of Dysphagia Screening After Acute Ischemic Stroke. Stroke. 2017;48 4:900-6; doi: 10.1161/STROKEAHA.116.015332.

45. Suntrup S, Kemmling A, Warnecke T, Hamacher C, Oelenberg S, Niederstadt T, et al. The impact of lesion location on dysphagia incidence, pattern and complications in acute stroke. Part 1: dysphagia incidence, severity and aspiration. European journal of neurology. 2015;22 5:832-8; doi: 10.1111/ene.12670.

46. de Jong G, Kessels F, Lodder J. Two types of lacunar infarcts: further arguments from a study on prognosis. Stroke. 2002;33 8:2072-6; doi: 10.1161/01.str.0000022807.06923.a3.

47. Del Bene A, Palumbo V, Lamassa M, Saia V, Piccardi B, Inzitari D. Progressive lacunar stroke: review of mechanisms, prognostic features, and putative treatments. International journal of stroke: official journal of the International Stroke Society. 2012;7 4:321-9; doi: 10.1111/j.1747-4949.2012.00789.x.

48. Bezerra DC, Sharrett AR, Matsushita K, Gottesman RF, Shibata D, Mosley TH, Jr., et al. Risk factors for lacune subtypes in the Atherosclerosis Risk in Communities (ARIC) Study. Neurology. 2012;78 2:102-8; doi: 10.1212/WNL.0b013e31823efc42.

49. Walker KA, Windham BG, Power MC, Hoogeveen RC, Folsom AR, Ballantyne CM, et al. The association of mid-to late-life systemic inflammation with white matter structure in older adults: The Atherosclerosis Risk in Communities Study. Neurobiology of aging. 2018;68:26-33; doi: 10.1016/j.neurobiolaging.2018.03.031.

50. Beard RS, Jr., Reynolds JJ, Bearden SE. Hyperhomocysteinemia increases permeability of the bloodbrain barrier by NMDA receptor-dependent regulation of adherens and tight junctions. Blood. 2011;118 7:2007-14; doi: 10.1182/blood-2011-02-338269.

\section{Figures}




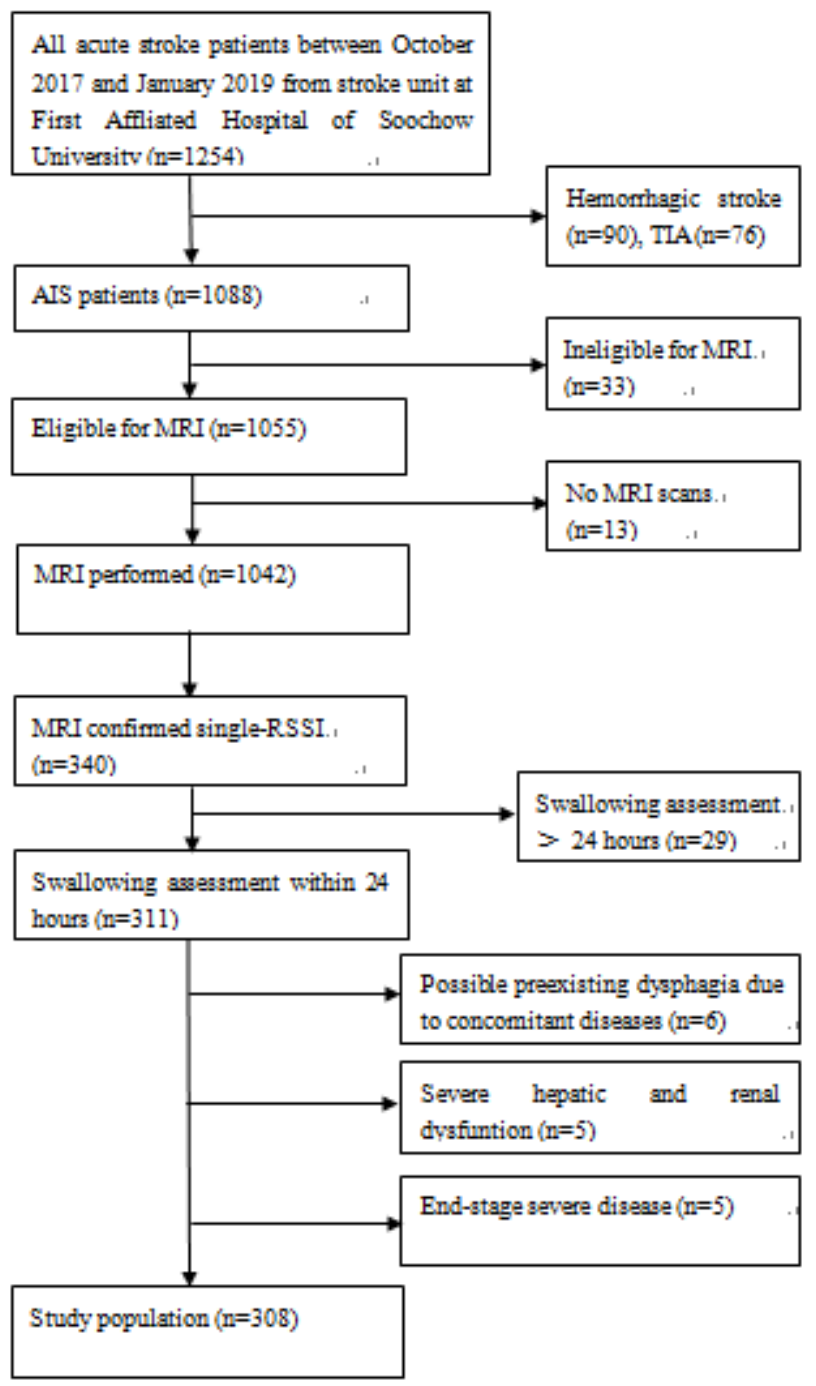

\section{Figure 1}

Details of study recruitment. AIS: acute ischemic stroke; TIA: transient ischemic attack. 


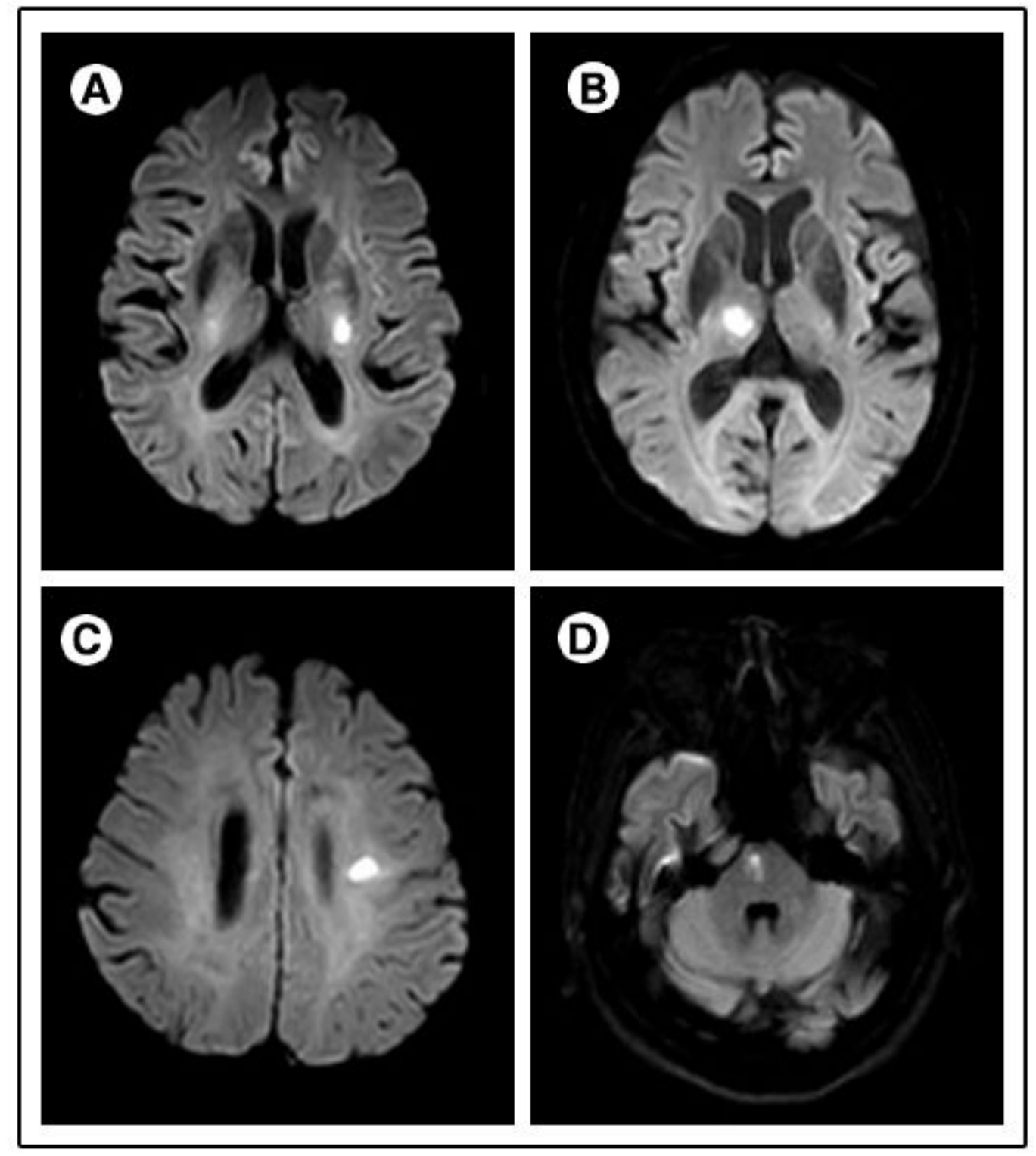

Figure 2

Examples for the four different single recent small subcortical infarcts locations on diffusion-weighted magnetic resonance imaging: basal ganglia $(A)$, thalamus (B), centrum semiovale (C) and pons (D) 


\begin{tabular}{|c|c|c|}
\hline MRI features & Definition and Score & MRI example \\
\hline $\begin{array}{l}\text { Cerebral microbleeds } \\
(\mathrm{CMBs})\end{array}$ & $\begin{aligned} \geq & 1 \text { CMBs } \\
& \quad(1 \text { point })\end{aligned}$ & (A) \\
\hline Lacunes & $\begin{array}{l}\geq 1 \text { Lacunes } \\
\quad(1 \text { point })\end{array}$ & \\
\hline $\begin{array}{l}\text { White matter hyperintensities } \\
(\mathrm{WMH})\end{array}$ & $\begin{array}{l}\text { Deep WMH } \\
\text { (Fazekas score } 2 \text { or } 3 \text { ) } \\
\text { or periventricular WMH } \\
\text { (Fazekas score } 3 \text { ) } \\
\text { (1 point) }\end{array}$ & 0 \\
\hline $\begin{array}{l}\text { Enlarged perivascular spaces } \\
\text { (ePVS) }\end{array}$ & $\begin{array}{l}\text { moderate to extensive } \\
(\geq 11) \mathrm{ePVS} \\
\text { (1 point) }\end{array}$ & D \\
\hline
\end{tabular}

\section{Figure 3}

Examples for the four different features of MRI-confirmed small vessel diseases: lacune (A), cerebral microbleeds (B), enlarged perivascular spaces (C), and white matter hyperintensities (D) 

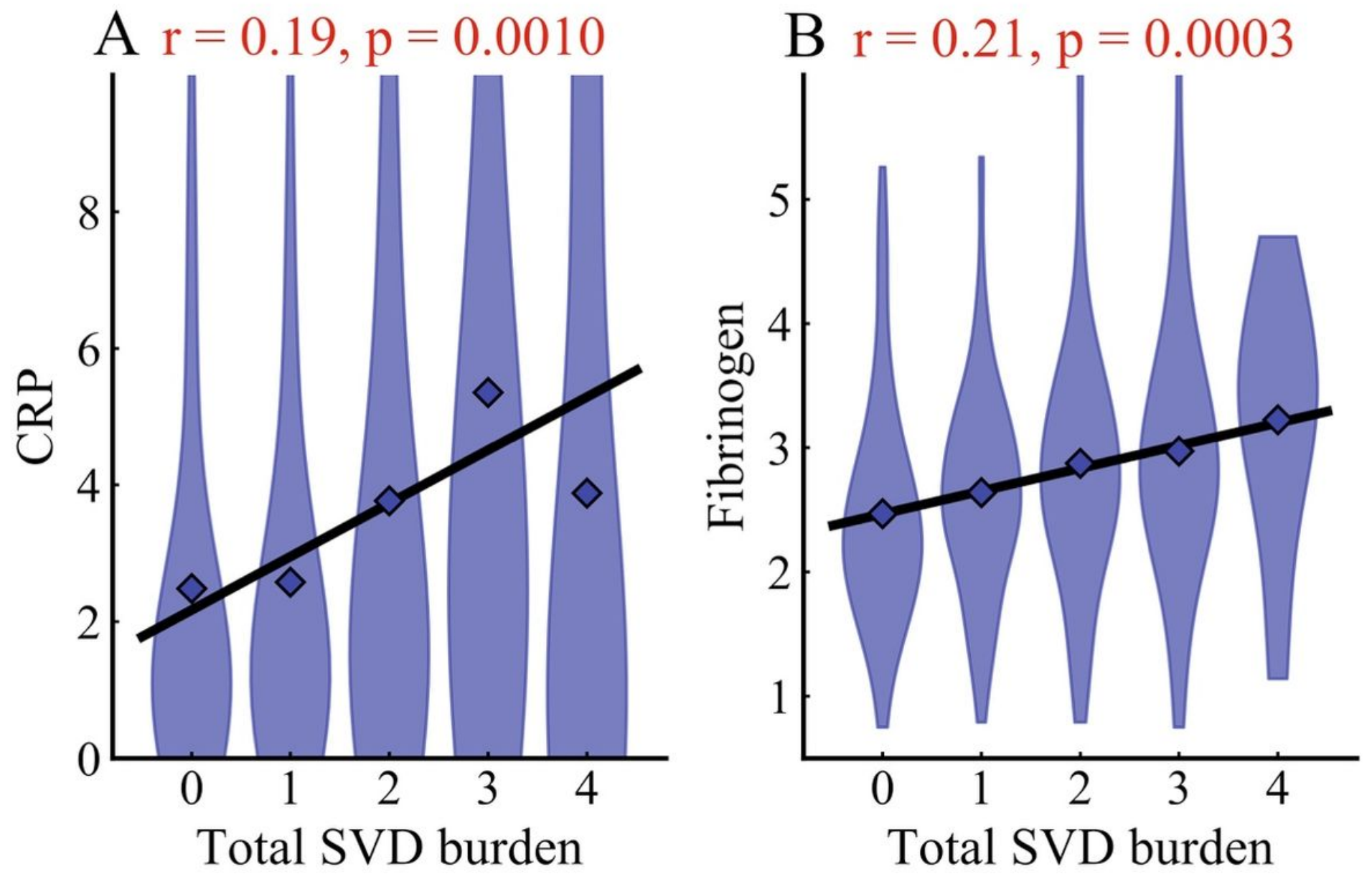

Figure 4

Linear correlation of plasma C-reactive protein and Fibrinogen with total SVD burden. * Panel A: Pearson correlations were conducted to analyze the relationships between plasma CRP and total SVD burden in single-RSSI patients $(r=0.19, p=1.00 \times 10-3)$. * Panel $B$ : Pearson correlations were conducted to analyze the relationships between plasma Fibrinogen (CRP) and total SVD burden in single-RSSI patients $(r=0.20$, $p=0.30 \times 10-3)$. 